\title{
Wastewater as an Indicator of Virus Circulation among Population of Dnipropetrovsk Oblast, Ukraine
}

\section{Maryna Bredykhina, Oleksandr Shtepa, Valentyna Rezvykh, Olena Paliychuk, Oleksandr Yurchenko, Svetlana Kovalenko, Inga Hernets}

State Institution Dnipropetrovsk Oblast Laboratory Center of the Ministry of Health of Ukraine, Dnipro, Ukraine

Objective

The purpose of the study was to confirm the hypothesis of possible intestinal viruses circulation in wastewater in Dnipropetrovsk Oblast, Ukraine.

Introduction

The main reservoir of intestinal viruses in the environment is human feces and contaminated wastewater. Sewage contamination preconditions further contamination of surface water serving as a source of water supply [1-3]. High resistance to physical and biological exposures ensures long-term survival of the viruses in water with various type and level of contaminants, especially in sewage. Detection of enteroviruses of a specific serotype in sewage indicates a significant number of people releasing the virus with feces [1,4]. There are two peaks of enteroviruses concentration in sewage: in January-April, and in June-September [3]. Sewage testing for enteroviruses is one of effective methods for their detection and risk assessment [5]. European region, including Ukraine, is recognized as free from of wild polioviruses, and a systematic study of sewage samples is important for identifying the possibilities of their "silent" circulation [6].

\section{Methods}

Wastewater samples from large sewerage collectors, sewage wells of infectious departments, city hospitals and district sewerage networks of Dnipropetrovsk Oblast were tested in 2007-2017 (39-64 samples monthly in the points are determined by the national regulations [2]). Gauze tampons (Moore's method) were used to collect wastewater [3]. In addition, samples were collected from wastewater flow into 1-liter sterile bottle with a sampler. Concentration was carried out using Enterosgel (hydroxyl methyl silicic acid) with high adsorption capacity [2]. The supernatant after all the concentration steps was used for culture on cell cultures RD, HEP-2, L20B [2,3,7].

In the presence of cytopathic action in RD cells, culture liquid was inoculated into L20B cells to detect clear cytopathic activity. Culture liquids were investigated to identify enteroviruses in neutralization reaction. In HEP-2, cytopathic effects were observed in the form of clusters of different sizes cells, "grape clusters", which indicated the presence of adenoviruses. Adenoviruses were confirmed by immunochromatographic tests for adenovirus antigens "Cito Test Adeno" Pharmasko, Ukraine).

\section{Results}

During 10 years, 150 viruses were isolated, 2 of them were a mixture of polioviruses. The frequency of detection of enteroviruses (including polioviruses) and adenoviruses was $2.5 \%$ (Tab 1$)$.

The isolated strains of enteroviruses, including polioviruses, were sent for confirmation the Public Health Center of the Ministry of Health of Ukraine and Regional WHO polio reference laboratories (Moscow and Helsinki). All polio strains were attributed to the vaccine strain Sabin. Also, the result Coxsackie viruses B typing was confirmed.

\section{Conclusions}

The data testify to presence of Picornaviridae (polioviruses, Coxsackie B, non-polio enteroviruses (NPEVs), and Adenoviridae in the wastewater in Dnipropetrovsk Oblast, Ukraine. The typical composition of viruses was not constant. Types 1, 2 polioviruses (Sabin) were occasionally isolated from wastewater. Type 2 polioviruses (Sabin) were isolated only in 2015. In 2009, 2012-2014, 2017, polioviruses did not stand out. Polioviruses isolation is associated with mass immunization of children against polioviruses carried out to maintain polio-free status of the country. In average, 150,000 children are vaccinated annually. Oral poliomyelitis vaccine (OPV) produced in Russia, France, Belgium was used in 2007-2017 (attenuated Sabin strains, 1,2,3 types). From April 2016, Ukraine refused to use trivalent OPV and switched to bivalent vaccine (Sabin strains, types 1 and 2). 
Sewage testing for polioviruses and their differentiation at WHO National and Regional Centers for Polio Diagnosis ensures a system for monitoring of possible "silent" circulation [6]. Sewage testing using cell cultures is one of the most affordable, effective and reliable methods for controlling the presence of viruses in the environment [2,3,7]. RD and L20B cell lines are useful for poliovirus isolation from sewage [7].

In addition to polioviruses, 1,2,3 types Coxsackie viruses B were isolated from wastewater samples. However, starting from 2013, Coxsackie viruses were isolated only in sporadic cases (Cox.vir.B5). In 2007-2011, NPEVs were isolated in some cases. Because polio is on the verge of eradication, more attention should be paid to study of NPEVs [8]. For 10 years, adenoviruses were isolated, which are well preserved in wastewater [4]. The maximum number of adenoviruses was isolated in 2014.

\section{Acknowledgement}

Authors are thankful to the State Institution Public Health Center of the Ministry of Health of Ukraine for confirmatory studies and dispatch of viral isolates to Regional WHO polio reference laboratory.

Authors also express their gratitude to specialists of regional reference laboratories in Moscow and Helsinki for studying viral isolates.

\section{References}

1. Mas Lago P, Gary HE, Jr, Perez LS, Caceres V, Olivera JB, et al. 2003. Poliovirus detection in wastewater and stools following an immunization campaign in Havana.vInternational. Int J Epidemiol. 32(5), 772-77. PubMed https://doi.org/10.1093/ije/dyg185

2. Sanitary-virological control of water bodies / Methodological recommendations approved by the order of the Ministry of Health of Ukraine, 30.05.2007, 284: 8.

3. Doan S., Zadorozhna V., Bondarenko V., Zubkova N., Burat T. Comparative characteristics of the isolation of enterovirus from water of various types in Ukraine. 2002,38-41.

4.Bofill-Mas S., lbinana-Gimenez N., Clemente-Casares P., Hundesa A., Rodriguez-Manzano J., Allard A., Calvo M., and Girones R. Quantification and stability of human adenoviruses and polyomavirus JCPyV in wastewater matrices. 2006. Appl. Environ. Microbiol. 72:7894-7896. PubMed https://doi.org/10.1128/AEM.00965-06

5. Hovi T, Shulman LM, van der Avoort H, Deshpande J, Roivainen M, et al. 2012. Role of environmental poliovirus surveillance in global polio eradication and beyond. Epidemiol Infect. 140, 1-13. PubMed https://doi.org/10.1017/S095026881000316X

6. 2007.World Health Organization Regional Office for Europe. Wild poliovirus isolated in Switzerland's sewer system, insignificant risk of outbreak. Monthly AFP surveillance bulletin.

7. Figas A, Wieczorek M, Litwinska B. 2017. W.GU. Detection of Polioviruses in Sewage Using Cell Culture and Molecular Methods. Pol J Microbiol. 65(4), 479-83. PubMed https://doi.org/10.5604/17331331.1227676

8. Fernandez-Garcia MD, Kebe O, Fall AD, Ndiaye K. 2017. Identification and molecular characterization of non-polio enteroviruses from children with acute flaccid paralysis in West Africa, 2013-2014. Sci Rep. 7, 3808World Health Organization (WHO). 
ISDS 2019 Conference Abstracts

Table 1. Sewage testing for enteroviruses (including polioviruses) and adenoviruses, 2007-2017, Dnipropetrovsk Oblast, Ukraine

\begin{tabular}{|c|c|c|c|c|c|c|c|c|c|c|c|c|}
\hline Years & $\begin{array}{c}200 \\
7\end{array}$ & $\begin{array}{c}200 \\
8\end{array}$ & $\begin{array}{c}200 \\
9\end{array}$ & $\begin{array}{c}201 \\
0\end{array}$ & $\begin{array}{c}201 \\
1\end{array}$ & $\begin{array}{c}201 \\
2\end{array}$ & $\begin{array}{c}201 \\
3\end{array}$ & $\begin{array}{r}201 \\
4\end{array}$ & $\begin{array}{c}201 \\
5\end{array}$ & $\begin{array}{r}201 \\
6\end{array}$ & $\begin{array}{c}201 \\
7\end{array}$ & Total \\
\hline Number of samples & 466 & 382 & 381 & 630 & 768 & 584 & 287 & 491 & 597 & $\begin{array}{r}72 \\
8\end{array}$ & 727 & 6041 \\
\hline$\%$ of positive samples & 3.0 & 1.8 & 1.8 & 3.0 & 3.4 & 3.4 & 2.7 & 3.4 & 2.4 & 0.9 & 1.4 & 2.5 \\
\hline Number of virus isolates, including: & 14 & 7 & 7 & 19 & 26 & 20 & 8 & 17 & 14 & 7 & 11 & 150 \\
\hline Poliovirus, type 1 & 1 & & & 2 & & & & & & & & $3 / 2.0 \%$ \\
\hline \multicolumn{13}{|l|}{ Poliovirus, type 2} \\
\hline Poliovirus, type 3 & 1 & 1 & & & 2 & & & & 1 & 2 & & $7 / 4.7 \%$ \\
\hline Mixture of polioviruses $1+3$ & & & & & & & & & 1 & & & $1 / 0.7 \%$ \\
\hline Mixture of polioviruses $2+3$ & & & & & & & & & 1 & & & $1 / 0.7 \%$ \\
\hline Coxsacki virus B1 & 3 & & 1 & 1 & & 4 & & & & & & $8 / 5.3 \%$ \\
\hline Coxsacki virus B3 & & 1 & & 1 & 7 & 2 & & & & & & $13 / 8.7 \%$ \\
\hline Coxsacki virus B5 & 2 & & 1 & 1 & 2 & 1 & & 1 & & & 3 & $10 / 6.6 \%$ \\
\hline Non-polio enterovirus & 2 & 1 & 1 & & 1 & & & & & & & $5 / 3.3 \%$ \\
\hline ECHO virus type 1-6 & & 1 & & & & & & & & & & $1 / 0.7 \%$ \\
\hline Adenovirus & 5 & 3 & 4 & 14 & 14 & 13 & 8 & 16 & 11 & 5 & 8 & $101 / 67.3 \%$ \\
\hline
\end{tabular}

